\title{
Game Analysis of Industry Chain Cluster Reconfiguration Mechanism
}

\author{
Huiting Hua ${ }^{1}$ and Lingle Wang ${ }^{2, *}$ \\ ${ }^{1} X i$ 'an Peihua College, Xi'an, Shaanxi, 710125, China \\ ${ }^{2} X i$ 'an Jiaotong University, Xi'an, Shaanxi, 710049, China \\ *Corresponding author. Email: wle8286@163.com
}

\begin{abstract}
Based on the behavioral choice conditions of enterprises and governments in the transferring and taking over places of industries to achieve industry chain cluster reconfiguration in two economic environments of freedom and intervention, this paper contrasts and analyzes the dynamic mechanisms to complete industry chain cluster reconfiguration. The study finds that: the conditions for the enterprises in the transferring place and the enterprises in the receiving place to choose to participate in the industry chain cluster reconstruction strategy depend on the chance of the other party choosing to participate in the strategy; the governments in the transferring place and the governments in the receiving place may fall into the "prisoner's dilemma" when they make a limited number of industry chain reconstruction transactions; the governments in the transferring place and the governments in the receiving place should be rewarded and punished in a certain way to make both parties choose to participate in the industry chain cluster reconstruction strategy. The incentive measures to make both parties choose the cooperation strategy consistently will lead to the cluster reconstruction of the industrial chain and maximize the interests of both parties.
\end{abstract}

Keywords: COVID-19 epidemic, Industrial chain, Industrial cluster.

\section{INTRODUCTION}

The global spread of the COVID-19 epidemic last year has caused the global industrial chain and supply chain to suffer different degrees of paralysis and breakage, triggering a wave of structural reconfiguration of the global industrial chain. And China's industrial chain and supply chain have long been deeply integrated with the global one [1]. Therefore, some of China's industrial chains must also undergo structural reconfiguration in order to enhance the security and stability of industrial chains and thus improve industrial competitiveness [2-4].

\section{GAME ANALYSIS OF INDUSTRY CHAIN CLUSTER RECONFIGURATION MECHANISM}

In this paper, when conducting the game analysis of industry chain cluster reconfiguration, it is assumed that there are two regions in China, one is the region where industry clusters are formed and the other is the region where no industry clusters are formed. According to the definition of classical industrial transfer, the author assumes that the region without industrial clusters is the place of industrial transfer, and the region with industrial clusters is the place of industrial undertaking. The actors of the game are the enterprises and government departments of the transferring and receiving regions, and the enterprises and government departments are assumed to be "economically rational" as participants. In other words, if the ratio of benefits and costs is greater than the ratio of benefits and costs before joining the cluster, enterprises will choose to join the cluster, otherwise they will choose not to join the cluster or leave the cluster. In addition, the industrial clusters in the paper are based on the network structure of industrial clusters, which shows the interaction between the enterprises in the transferring place and the enterprises in the taking place and other elements in the cluster area, and thus highlights more the inter-industry correlation. 


\subsection{Game Analysis of Industry Chain Cluster Reconfiguration Mechanism from The Perspective of Enterprises}

It is assumed that the enterprises in the transferring and receiving regions have two choices when faced with the government's industrial transfer policy to manage the epidemic: to participate in industrial transfer and not to participate in industrial transfer, i.e., to cooperate or not to cooperate. Let the enterprise in the transferring place be enterprise 1 and the enterprise in the taking place be enterprise 2; the cost of cooperation of enterprises is $\left.c_{i} \in 0, \infty\right), c_{i}$ is a random variable obeying the distribution function $F\left(c_{i}\right)$; the distribution density $f\left(c_{i}\right)$ is strictly greater than zero, $c_{1}$ and $c_{2}$ are independent of each other; the probability that enterprise 1 chooses to cooperate is $F\left(c_{1}\right)$ and the probability that it does not cooperate is $1-F\left(c_{1}\right)$; the probability that enterprise 2 chooses to cooperate is $F\left(c_{2}\right)$ and the probability that it does not cooperate is $1-F\left(c_{2}\right)$. If only one enterprise cooperates, that is, only one local enterprise participates in the industry chain reconstruction, the profit function of the cooperating enterprise $i$ is $y^{d}-c_{i}$, and the profit of the non-cooperating enterprise is zero; if two enterprises cooperate, that is, the enterprises in the transferring place and the undertaking place both participate in the industry chain reconstruction, the profit function of the enterprise $i$ is $y^{s}-c_{i}$; if no enterprise cooperates, that is, the enterprises in the transferring place and the undertaking place both do not participate in the industry chain reconstruction, the profit is zero; and $y^{d}>y^{s}>$ 0 . According to the relevant equilibrium theory, the established gain matrix of inter-firm participation in industry chain reconfiguration is shown in Table 1.

Table 1. Gain matrix of inter-enterprise game

\begin{tabular}{|c|c|c|c|}
\hline \multicolumn{2}{|c|}{} & \multicolumn{2}{c|}{ Enterprise 2 } \\
\cline { 3 - 4 } \multicolumn{2}{|c|}{} & Cooperation & $\begin{array}{c}\text { Non- } \\
\text { cooperation }\end{array}$ \\
\hline \multirow{3}{*}{$\begin{array}{c}\text { Enterprise } \\
1\end{array}$} & Cooperation & $\begin{array}{c}y^{s}-c_{i}, \\
y^{s}-c_{i}\end{array}$ & $y^{d}-c_{i}, 0$ \\
\cline { 2 - 4 } & $\begin{array}{c}\text { Non- } \\
\text { cooperation }\end{array}$ & $0, y^{d}-c_{i}$ & 0,0 \\
\hline
\end{tabular}

Through industrial transfer, to achieve industrial chain reconstruction, enterprise 1 in the transferring place and enterprise 2 in the undertaking place must choose to cooperate, i.e., participate in industrial chain reconstruction together. According to the Bayesian Nash equilibrium rule, the conditions for realizing the cooperation of enterprise 1 and enterprise 2 are shown in Equation (1). $\left\{\begin{array}{l}c_{1}=\left(y^{s}-y^{d}\right) F\left(c_{2}\right) \\ c_{2}=\left(y^{s}-y^{d}\right) F\left(c_{1}\right)\end{array}\right.$

From Equation (1), it can be concluded that the attitude of enterprises in the transferring place choosing to cooperate is influenced by the probability of enterprises in the undertaking place choosing to cooperate, and conversely, the attitude of enterprises in the undertaking place choosing to cooperate is influenced by the probability of enterprises in the transferring place choosing to cooperate. Therefore, considering the industry chain cluster reconstruction from the enterprise side only, the size of the probability of both sides choosing cooperation directly determines the industry chain and whether the reconstruction can be carried out. The probability that both the transferring enterprises and the undertaking enterprises choose to cooperate is mainly influenced by three factors: firstly, the high or low cost of enterprise cooperation; secondly, the degree of preferential policies related to industrial transfer or undertaking in the two regions; thirdly, the high or low market barriers in the two regions, etc. However, due to the information asymmetry between the enterprises in the transferring place and the enterprises in the undertaking place, there is also the phenomenon of "lemon market", that is, the enterprises in the transferring place and the enterprises in the undertaking place are not fully matched when the industrial chain is reconstructed.

In addition, as China allows different regions to take different measures to control the epidemic, local governments tend to restrict the transfer of industries in their own regions in order to maximize local interests, resulting in serious market segmentation between regions, especially high barriers to entry in inter-provincial markets. Therefore, in order to recover the economy and realize the industrial transformation and upgrading of China, game analysis from the behavior of local governments is also needed when reconstructing the industrial chain [5].

\subsection{Game analysis of industry chain cluster reconfiguration mechanism from government perspective}

If the local governments of two regions choose to cooperate, then both can get the benefit as $\pi_{1}$; if one party chooses to cooperate and the other party chooses not to cooperate, then the benefit obtained by the party who chooses to cooperate is $\pi_{2}$ and the benefit obtained by the party who chooses not to cooperate is $\pi_{3}$; if both parties choose not to cooperate, that is, compete with each other, then the benefit obtained by each is $\pi_{4}$. Meanwhile, set $\pi_{3}>\pi_{1}>\pi_{4}>\pi_{2}[6]$. 


\subsubsection{Game Analysis of Industry Chain Reconfiguration Mechanism of Free Choice}

(1) Scenario 1: The gain matrix of both sides in one game between local governments is shown in Table 2 .

Table 2. Gain matrix of one game between governments

\begin{tabular}{|c|c|c|c|}
\hline \multicolumn{2}{|c|}{} & \multicolumn{2}{c|}{ Enterprise 2 } \\
\cline { 2 - 4 } & Cooperation & $\begin{array}{c}\text { Non- } \\
\text { cooperation }\end{array}$ \\
\hline \multirow{2}{*}{$\begin{array}{c}\text { Enterprise } \\
1\end{array}$} & $\begin{array}{c}\text { Cooperatio } \\
n\end{array}$ & $\pi_{1}, \pi_{1}$ & $\pi_{2}, \pi_{3}$ \\
\cline { 2 - 4 } & $\begin{array}{c}\text { Non- } \\
\text { cooperatio } \\
n\end{array}$ & $\pi_{3}, \pi_{2}$ & $\pi_{4}, \pi_{4}$ \\
\hline
\end{tabular}

From Table 2, we can get: if the game between two regional governments is only once, because $\pi_{3}>\pi_{1}$, so, the government of the industrial transferring place may adopt many restrictive policies for the sake of local economic development, which makes the cost of industrial transfer great; in addition, the government of the industrial undertaking place is not enough to assess the incoming industries and gives insufficient preferential measures, or is not very attractive to industrial transfer, which eventually causes both sides fall into "Prisoner's Dilemma" and makes the industrial chain cross-regional reconstruction into a deadlock. At the same time, because of the opportunistic behavior of the two regional governments, the regional overall interests of our country are not maximized. Therefore, since the reconfigured industrial chain still needs time to test its effect and there are still different degrees of time lag in the impact of the epidemic on the industrial chain, it is necessary to introduce repeated game theory to change the period expectation of local governments on industrial transfer or industrial chain reconfiguration.

(2) Scenario 2: Analysis of the benefits of both sides when an infinite number of repeated games are played between local governments

Because there is a coexistence relationship between two local governments in the long term, if one party adopts a non-cooperative behavior strategy in one period, i.e., it does not participate in the industry chain reconstruction, its benefit in this period is $\pi_{3}$, this behavior will cause the other local government to take retaliatory measures in the next period, i.e., it also adopts non-cooperation, resulting in each local government choosing not to cooperate in each subsequent period, i.e., both the undertaking and the transferring governments do not participate in the the industrial chain reconfiguration, and each time the benefit to each party is $\pi_{4}$. Using $\lambda$ to represent the discount rate indicating future benefits, if one party often adopts a non-cooperative attitude, it indicates that it attaches importance to short-term benefits, implying that the value taken of $\lambda$ is small, the probability of industrial transfer occurring smoothly between the two parties is small, and the chance of realizing industrial chain reconstruction is small. Therefore, the expected benefits of the non-cooperative strategy are shown in Equation (2).

$\mathrm{R}_{3}=\pi_{3}+\lambda \pi_{4}+\lambda^{2} \pi_{4}+\cdots+\lambda^{\mathrm{n}} \pi_{4}=\pi_{3}-\pi_{4}+\frac{\pi_{4}}{1-\lambda}(2)$

If both the transferring and receiving governments choose the strategy of active cooperation, i.e., both parties actively participate in the industry chain reconstruction, the gain in each period is $\pi_{1}$, then the future estimated gain for both parties adopting the cooperation strategy is shown in Equation (3).

$\mathrm{R}_{1}=\pi_{1}+\lambda \pi_{1}+\lambda^{2} \pi_{1}+\cdots+\lambda^{\mathrm{n}} \pi_{1}=\frac{\pi_{1}}{1-\lambda}$

To achieve the industry chain reconstruction, it is necessary for the governments of the transferring and undertaking places to adopt active and cooperative policies or measures, i.e., to adopt a cooperative attitude, which must be made $R_{1} \geq R_{3}$. Therefore, the solution is shown in Equation (4).

$\lambda^{*}=1-\frac{\pi_{1}-\pi_{4}}{\pi_{3}-\pi_{4}}$

From Equation 4, it can be seen that: $\lambda^{*}$ is the minimum value of discounting the gains of each party in different periods when the transferring and undertaking governments allow the industrial transfer and each party chooses a cooperative strategy and participates in the reconstruction of the industrial chain, which leads to Pareto improvement; the gains from the transferring and undertaking governments adopting cooperation and non-cooperation jointly determine the range of values of $\lambda^{*}$. The greater the gains of the parties' non-cooperation, the smaller the possibility of smooth industrial transfer, and the less chance of cross-regional reconfiguration of the industrial chain. Therefore, in order to achieve the optimal coordination of the overall interests of the regional economy, the subjects at each level of industrial transfer should give more consideration to the benefits of cooperation, i.e., the governments of the transferring and undertaking places should choose a cooperation strategy. For the long-term development of the regional economy, the governments of the transferring and undertaking places must be given certain incentives to adopt. 


\subsubsection{Game analysis of Industrial Chain Reconstruction under Intervention Mechanism}

At the same time, in order to avoid breeding rent-seeking behavior or corruption, it is necessary to make the governments of transferring and undertaking places choose the cooperation strategy within a limited period of time, and adopt the central government as a third party to provide enough incentive strategies to promote the smooth transfer of industries and realize the industrial chain reconstruction. In order for the government of the transferring place and the government of the receiving place to achieve the cooperation strategy of promoting "mutual benefit and win-win", assume that the central government will give a certain percentage of incentives to the government of the transferring place or the government of the receiving place for choosing the policy of encouraging industrial transfer $\rho$, which is $\rho$ times of the benefit they get by choosing the cooperation strategy; similarly, if one of the governments of the transferring place or the government of the undertaking place chooses the policy of restricting industrial transfer, which is not conducive to the industrial chain reconstruction, the central government gives the party that chooses the non-cooperative strategy a penalty measure, which is $\rho$ times of the gain it obtains, $0<\rho<1$.

Table 3. Gain matrix of the game between local governments under the intervention mechanism

\begin{tabular}{|c|c|c|c|}
\hline \multicolumn{2}{|c|}{} & \multicolumn{2}{c|}{ Enterprise 2 } \\
\cline { 3 - 4 } & Cooperation & $\begin{array}{c}\text { Non- } \\
\text { cooperation }\end{array}$ \\
\hline \multirow{3}{*}{ Enterprise 1 } & Cooperation & $\pi_{1}, \pi_{1}$ & $\begin{array}{l}(1+\rho) \pi_{2},(1 \\
-\rho) \pi_{3}\end{array}$ \\
\cline { 2 - 4 } & $\begin{array}{c}\text { Non- } \\
\text { cooperation }\end{array}$ & $\begin{array}{l}(1-\rho) \pi_{3},(1 \\
+\rho) \pi_{2}\end{array}$ & $\pi_{4}, \pi_{4}$ \\
\hline
\end{tabular}

From Table 3, it can be concluded that the cooperation strategy is the optimal choice for the transferring and undertaking governments when the condition $\pi_{1}>(1-\rho) \pi_{3}$ is met. If one of the transferring or undertaking governments chooses not to cooperate, the greater the gain $\pi_{3}$, the greater the penalty $\rho \pi_{3}$ given to it; similarly, the greater the gain $\pi_{2}$, the greater the reward $\rho \pi_{2}$ given to the party that chooses to cooperate.

In conclusion, the introduction of a comprehensive incentive mechanism to restrain the competition and cooperation relationship between local governments in industrial transfer can maximize the overall gain, and when the reward or punishment coefficient reaches a certain threshold value, it can motivate local governments in industrial transfer to choose the cooperation strategy within a limited period.

\section{CONCLUSION AND COUNTERMEASURES}

Based on the above analysis, this paper draws the following conclusions: the conditions for the enterprises in the transferring place or the undertaking place to choose to participate in the strategy of industry chain cluster reconstruction depend on the chance that the other party chooses to participate in the strategy; the governments of the transferring place and the undertaking place may fall into the "prisoner's dilemma" when they make the trade of industry chain reconstruction in a limited number of times; some certain incentives and penalties should be adopted on the governments of the transferring place and the undertaking place to make both parties choose the cooperation strategy consistently, which will promote the industry chain cluster reconstruction and maximize the interests of both parties.

Therefore, this paper proposes the following countermeasures.:

First, introduce the intervention mechanism for the main body of industrial chain reconstruction to strengthen the competitiveness and stability of industries. Adopting a laissez-faire policy for the enterprises and governments in the transferring places and undertaking places will greatly reduce the effect of industrial chain reconstruction. At the same time, it will produce negative externalities such as "lemon phenomenon", "opportunism" or "rent-seeking behavior", which will not only be detrimental to China's industry to get out of the shadow of the epidemic, but also deteriorate the stability and security of the industrial chain. Therefore, with reference to the conclusion of this paper, government intervention mechanism can be appropriately introduced so that enterprises and governments in the transferring places and undertaking places can participate in the reconstruction of China's industrial chain under certain conditions, and finally enhance the flexibility and resilience of China's industrial chain.

Second, optimize the regional business environment to create good external conditions for the industrial chain reconstruction. The business environment of a region directly determines the external conditions of whether the industrial chain in the industrial cluster in that region can be reconstructed. It is necessary to optimize the regional business environment from the perspective of cross-regional economic growth in order to accommodate the cross-regional transfer and clustering of industrial chains. Therefore, in order to realize industrial chain reconstruction through industrial 
clusters, it is necessary for the regions of industrial clusters to continuously optimize and improve supporting policies, use incentive and constraint mechanisms, encourage cooperation and coordination among enterprises in industrial clusters, realize risk-sharing and benefit-sharing mechanisms, bring into play the positive externalities of industrial clusters in the process of industrial chain reconstruction, and improve the new competitiveness of industries.

Third, use the opportunity of industrial chain reconstruction to reshape the international status of China's industrial chain. Most of China's industrial chains are at the low end of the global value chain, with low value-added industries and fragile industrial chains that are vulnerable to the external environment. Therefore, in the trend of global industrial chain restructuring, our country should take the initiative to restructure the industrial chain first, adjust the structure of our industrial chain and carry out the adjustment of the regional layout of industries, form the regional industrial chain agglomeration effect, and attract multinational companies to transfer some industries to China. At the same time, improve the shortcomings of China's industrial chain, play the external economy of industrial chain agglomeration, form a positive feedback mechanism, promote China's industrial chain into a higher value chain, thus enhancing the international competitiveness of China's industry.

\section{REFERENCES}

[1] Monan Zhang. The global change behind the restructuring of the industrial chain between China and the United States[J]. Finance and Economics,2020(05):1.

[2] M.Y. Liu, M.J. Rui. Value network reconfiguration, division of labor evolution and industrial structure optimization[J]. China Industrial Economy,2012(05):148-160.

[3] Zhibiao Liu. The new trend of economic globalization and global industrial chain cluster reconfiguration under the clusters under the COVID-19 epidemic[J]. Jiangsu Social Science,2020(04):16-23+241.

[4] R. Mario, S. Nicola, K. Christian, et al. Navigating disruptive crises through service-led growth: the impact of COVID-19 on Italian manufacturing firms[J]. Industrial Marketing management,2020,88(7):225-237.

[5] Yan Wang. Analysis of factors influencing the formation of innovation mechanism of logistics industry cluster[J]. China circulation economy,2009,23(07):35-38.

[6] Shiyu Xie. Economic game theory [M]. Shanghai: Fudan University Press, 2017.2 (reprinted 2018.8): 72-162. 